\title{
Physical, Digital, and Hybrid Setups Supporting Card-Based Collaborative Design Ideation
}

\author{
Caroline Lundqvist ${ }^{1}$, Daniel Klinkhammer ${ }^{2}$, Kim Halskov ${ }^{1}$, Stefan Paul Feyer ${ }^{2}$, \\ Jeanette Falk Olesen $^{1}$, Nanna Inie ${ }^{1}$, Harald Reiterer ${ }^{2}$, and Peter Dalsgaard ${ }^{1}$ \\ ${ }^{1}$ CAVI, Aarhus University \{carem, dalsgaard, jfo, inie, halskov\}@cavi.au.dk \\ ${ }^{2}$ HCI Group, University of Konstanz \{daniel.klinkhammer, stefan.feyer, harald.reiterer\}@uni.kn
}

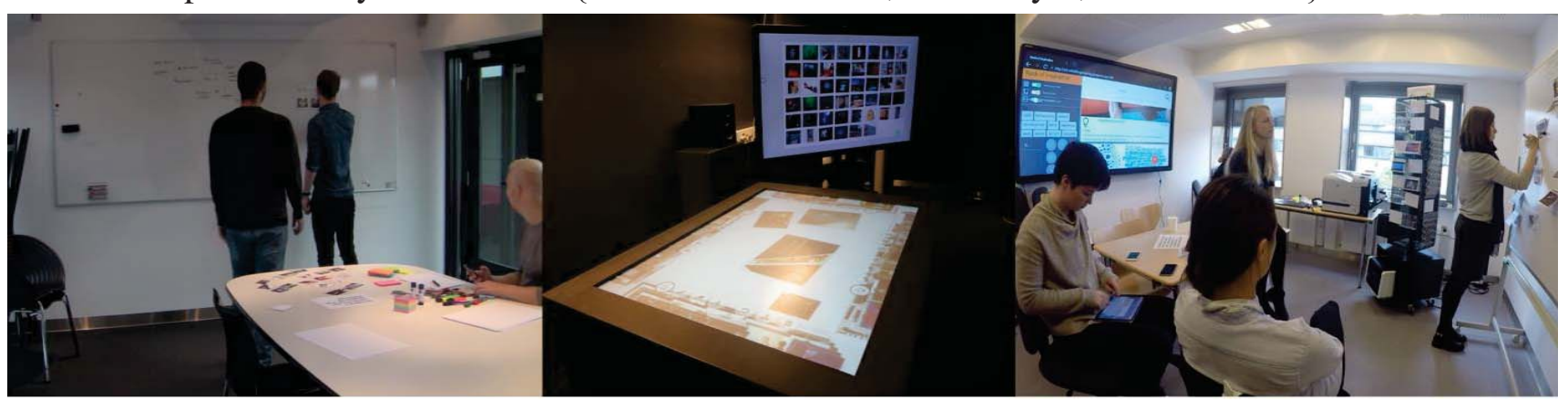

Figure 1. Pictures of the three setups: (left) Physical: shows the ICW setup with a whiteboard in the background and a table with inspiration cards, pens, paper, sticky notes on it. (center) Digital: shows the iCard setup, with the interactive tabletop in the middle and the vertical screen to the right side. (right) Hybrid: shows the RoI setup, with a vertical display shown in the left side, and the rack and a whiteboard in the right side. Tablets, smartphones and materials, such as pens, paper, sticky notes, were also available.

\section{ABSTRACT}

Physical tools and materials like pen, paper, sticky-notes, and whiteboards are commonly used in collaborative creative design processes, whereas digital tools play a more marginal role. But what are the benefits and drawbacks of physical, digital, and hybrid physical-digital setups when it comes to supporting collaborative ideation? To answer this question, we present a study and analysis of three different implementations of a well-established collaborative ideation technique called Inspiration Card Workshop, with physical, digital, and hybrid setups. Each setup is a controlled experiment with three different groups of designers. We analyse the setups in terms of how they support five key aspects of collaborative design. Based on our insights, we present implications for future use of digital tools to support card-based collaborative design ideation, in which we argue for a technically lightweight hybrid workflow setup that builds on well-proven physical and digital components.

\section{Author Keywords}

Design tools; creativity support tools; ideation; cross-surface interaction; digital versus physical; collaboration.

\section{INTRODUCTION}

Collaborative creative sessions and workshops are commonplace in design and are often central to driving ideation and concept development. Physical tools and materials can play a major part in these sessions, e.g., the shape of pen, paper, sticky-notes, and whiteboards that participants use to explore and express ideas, and to discuss and iterate on concepts. Digital tools, on the other hand, often play a marginal role in such collaborative events. This holds true even in cases where the intended end-product is digital, e.g., when interaction designers develop concepts for new prototypes. To interaction design researchers who are familiar with the potential of digital technologies, this can seem paradoxical. Yet, it indicates that physical tools have a number of benefits that make them well-suited for these particular activities, and that developing digital tools that support or augment collaborative creative processes is a highly complex challenge. There are a number of potential explanations for this. For instance that physical materials and tools might be more familiar and accessible and thus lend themselves better to these types of activities; that physical setups allow for users to better externalise design ideas and 
make use of their spatial intelligence; the specific benefits of existing digital setups, which are useful in other use-cases, might be less useful in collaborative ideation setups; and the dynamic transitions between individual and collaborative work that have been shown to be prevalent in collaborative creative work $[11,19]$ might be hampered by current digital interfaces, which are typically designed around a single-user paradigm and lack support for users to smoothly transition between individual and collaborative sub-activities.

We need a better understanding of these issues and their potential interrelations if we are to develop setups to better augment collaborative creative work. This forms the motivation for our work in this paper, which examines the implications of using physical, digital, or hybrid setups to support collaborative ideation workshops. In order to examine and compare these three different setups supporting one specific and well-established collaborative ideation method, Inspiration Card Workshops [18 $]^{1}$ we tested each setup with three different design teams, who were given similar design tasks to answer the following research question: What are the benefits and drawbacks of using physical, digital, and hybrid setups when conducting Inspiration Card Workshops, and how do the different setups influence the process?

We offer both an overview of the quantitative findings from the study and a more in-depth qualitative analysis with a particular emphasis on five principles for collaborative design on which the Inspiration Card Workshop method is based: no prerequisite skills and simple rules, mutual learning, collaborative ideation, combinatorial creativity, and externalization of ideas. Based on our insights, we present implications for future use of digital tools to support card-based collaborative design ideation. The intended audience of the paper are design researchers, for whom we indicate directions for research into employing and combining digital and physical components in design ideation, as well as design practitioners, for whom we present advise on how to set up and facilitate ideation sessions.

\section{RELATED WORK}

\section{Card-based design methods}

Numerous methods and approaches have been developed to facilitate ideation, a core component of creative processes. Smith [36] has identified 172 distinct methods for ideation, and several works present further arrays of ideation methods $[26,31]$. In this paper, we focus on a particular subset of ideation methods, namely collaborative ideation supported by card-based techniques [29]. Specifically, we examine one distinct method, Inspiration Card Workshops (ICW). In their overview of card-based design methods, Wölfel and Merritt [39] suggest that these methods owe a significant portion of their popularity to cards being simple, tangible, and easy to manipulate. This makes it easy for most participants in a design process to understand and use cards in collaborative events, regardless of their design expertise or skills. Lucero and Arrasvuori $[27,28]$ show that these characteristics make cards a particularly suitable medium for introducing information and snippets of inspiration into a design process. Given these qualities, there are a wide range of card-based design methods, for instance PLEX cards [27] the Sound Design Deck [1], Video Card Game [5], Card Sorting [22] and PictureCARDs [37]. While some are open-ended, e.g. Oblique Strategies [10] and IDEO Method Cards [23], most of these techniques are designed for a specific phase or event in the design process. In relation to our research objective, one of the main take-aways from this work is that the tangible nature of cards is a main reason for their popularity and relative success in collaborative design methods. However, this represents a major challenge if we wish to explore how they can be supplemented or augmented with digital means: is it feasible to gain (some of) the benefits of digital components without detracting from the features that make cards beneficial in collaborative design?

\section{Hybrid and digitally supported design methods}

A number of research teams have examined setups that try to achieve this by employing digital technologies to partially or fully augment design methods that have similarities with Inspiration Card Workshops. The Affinity Table [13] combines pen and paper-based sticky notes with an interactive table with tangibles, and a vertical display, which provides an overview over the complete workspace. Participants start by creating paper sticky notes, which are digitalized when placed on the interactive table. Physical tokens can be employed to cluster and arrange these digitalized sticky notes. In this way, the Affinity Table seeks to preserve the physical workflow while adding digital functionalities such as easy clustering by auto-alignment, searching for images on the web and putting them on digital sticky notes, or automatically recording the whole generation and clustering process of cards. Idea Playground [33] is a digital whiteboard with manifold ways of inputting data from different sources. The setup preserves an individual design space, provides a fluent transition from the physical into the digital world, and grants freedom of structuring digital

\footnotetext{
${ }^{1}$ According to Google Scholar the original Inspiration Card Workshops paper has 172 citations - excluding those papers with less than five citations or with one of the authors of the original article as authors leaves 47 citations.
} 
artifacts. Dazzle [32] provides the transmission from the physical to the digital domain at a later point in the process. It consists of a vertical shared display and multiple personal displays. The artifacts can be sent to the screen where they are shared with the other participants. A log represents the statuses of the design area. Studies have shown that Dazzle facilitated group conversation, but the shared display was rarely used. Pictionaire [20] uses overhead images on a tabletop to combine physical artifacts with digital annotations. The setup supports sharing and discussion and also provides a storyboard tool to develop design concepts. The division between the digital and physical artifacts was greatly reduced, but their evaluation showed that the physical artifacts still outperform the digital artifacts.

With physical artifacts, it is easy to divide a design area in personal and collaborative spaces. However, digital setups typically come with hardware restrictions that makes this hard to achieve. Some digital tools try to mimic physical artifacts, preserving specific physical attributes but enhancing the process with digital elements. For instance, the Affinity Table preserves individual ideation by using sticky notes, which are digitized afterwards and then using a collaborative table top with tangibles for the collaborative work. Dazzle also stays completely physical until generated ideas have to be stored. Team Storm [15] uses personal screens with pen input for individual ideation, with options to share it on a shared vertical display for collaborative work. The Designer's Environment [38] also uses mobile devices for individual work, while the collaborative work takes place on a tabletop.

Our work builds on the previous research outline above by comparing a physical, a digital, and a hybrid setup supporting the same ideation method, Inspiration Cards Workshops.

\section{PHYSICAL, DIGITAL, AND HYBRID INSPIRATION CARD WORKSHOP SETUPS}

The abovementioned creativity support tools differ a) in the degree to which they employ digital components, b) in terms of how and when they transition from the physical into the digital domain during the ideation process, and c) in terms of the ways in which they support individual and collaborative ideation. While these studies of design tools provide interesting examples and a more nuanced understanding of each approach in detail, they are so different from one another that they can be hard to compare especially because they use very different supporting materials. In order to get a better understanding of the benefits and limitations of physical and digital tools for supporting collaborative ideation, we have therefore chosen to study one particular card-based design ideation method, the Inspiration Card Workshop, in three implementations: 1) The classic physical Inspiration Card Workshop (ICW), 2) The purely digital
iCard setup (iCard), and 3) the hybrid Rack of Inspiration (RoI) setup.

The Inspiration Card Workshop method is inspired by Participatory Design [14,17,34,35] and informed by insights from Creativity Studies [24] and Distributed Cognition [21]. The participatory approach entails that the method has been developed to enable participants with different backgrounds and skillsets to contribute on equal footing to the development of new design concepts. Moreover, the method embodies a set of principles, which we will describe here in more detail since these are important for understanding how and why the method works under specific conditions and setups:

1) Simple rules and no prerequisite skills: The method should be easily accessible, requiring no lengthy introduction or rules, nor require specific skillsets, in order to have a low barrier to entry for different stakeholders.

2) Mutual Learning: The method should support mutual learning, in the sense that it should both enable designers to get a better understanding of the use domain and enable participants from a use domain to get a better understanding of new technologies.

3) Collaborative Ideation: The method should support collaborative ideation and negotiation of ideas [2], so that the different stakeholders can develop and explore ideas together.

4) Combinatorial Creativity: To meet the aforementioned principles of mutual learning and collaboration, the method should afford combinatorial creativity as a means for bringing domain knowledge and technology insights together in novel ways [4]. Combinatorial creativity [4] refers to the creation of novel ideas and concepts through combination of one or more familiar ones. It is a common process in many creative domains, as demonstrated by [25], who proposes the term bisociation of matrices to define the process by which two concepts from different domains are brought meaningfully together to form a novel one.

5) Externalization of ideas: The method should enable externalization of ideas, both because this can strengthen the process of establishing shared understandings [7], and because cognitive offloading [9] into material artifacts has been shown to be central to the process of imagining and exploring potential future situations in design [12].

In the following, we will describe the original way of carrying out Inspiration Card Workshops by use of physical materials and tools such as physical inspiration cards, posters, sticky notes, pens etc. We will subsequently present the iCard developed by CAVI at Aarhus University [16] and the Rack of Inspiration developed by our lab at Konstanz University.

\section{Inspiration Card Workshops: A Physical Setup}

An Inspiration Card Workshop is a collaborative design ideation activity involving professional designers and 
domain participants and intended for the early stages of the design process and, in which domain and technology insights are combined to create design concepts (see Figure 1 - left). The workshop is organized into three parts: introduction, combination and co-creation, and presentation of concepts. Furthermore, there is an initial preparation phase and a subsequent processing phase (see Table 1).

In the preparation phase the designers and other stakeholders gather inspiration from a) the intended use domain and b) technologies that could be employed in novel design concepts. These sources of inspiration are gathered through studies of the domain and represented as images on cards, which may be accompanied by text descriptions. Technology Cards can be either specific installations or more generic technologies like camera tracking, mobile apps etc. The purpose of the preparation phase is to establish an overview of the design space at hand and to select a set of sources of inspiration that are open enough to spur novel concepts, yet, at the same time, limited enough in scope, that participants can get an overview and shared understanding of the sources in the timeframe of the workshop. The start of the workshop proper consists of a brief introduction of each card. The main combination and co-creation phase consists of the participants collaborating by combining the different cards, thus generating novel concepts that combine aspects of the design domain with one or more technologies. The combination of concepts from a design domain via Domain Cards and technological concepts via Technology Cards can thus be understood as a structured approach to fostering combinatorial creativity through bisociation of matrices [4, 25]. Participants are prompted to generate as many concepts as possible. Typically, the cards are spread out onto a table, around which the participants are seated. There are no rules for turn-taking; instead, participants are encouraged to discuss the cards and affix them to poster-sized pieces of cardboards, and to add text or visuals to explain and refine the concepts. These concept posters, which constitute the outcome of the combination and co-creation phase, are revisited and presented in the presentation phase, in which participants also discuss and evaluate the concepts. In order to disseminate the concepts, the workshop organizers typically photocopy the concept posters and email them to participants as part of the final processing phase.

\section{iCard: A Fully Digital Setup}

For the preparation phase, a web repository, at digitalexperience.dk, supports the selection and production of Technology Cards. The website is a custom designed repository, in which each entry consists of a short presentation of an innovative technology or application, in most cases supported by a video. Workshop organizers can create and save their own collection of Technology Cards from more than 500 entries. Moreover, the iCard environment provides support for uploading images, which are transformed into Domain Cards. Two multitouchscreens, one vertically mounted on a table, and a horizontal one, both running our custom-developed and the freely available iCard web-app, supporting the workshop proper (see Figure 1 - center). Technology and Domain Cards can easily be uploaded to both multi-touchscreens. The vertical screen is used for the presentation of the cards and here video associated with a card can be played. For the combination and co-creation phase, the cards are available at the edges of the horizontal screen. Users can drag cards to the centre of the screen and use the available drawing and text tools for annotation and elaboration of the design concept developed. By pushing a save button, the central part of the screen is captured, saved and made available as a digital concept poster at the vertical screen saving the collection of concept posters for subsequent processing. For the final presentation phase, the concepts developed can be presented one at a time in full-screen on the vertical screen. After the workshop, all participants can access all posters and cards via a web browser.

\section{Rack of Inspiration: A Hybrid Setup}

Basis of the Rack of Inspiration is a turn-able, roll-able perforated plate stand (see Figure 1 - right). At its bottom a printer is located. At the perforated plates are several attachments: cardholders to deposit cards, magnetic whiteboard foil for labelling, e.g., the holders, a box with sketching materials, a whiteboard filling one complete side of the stand and iPads attached by magnets. The
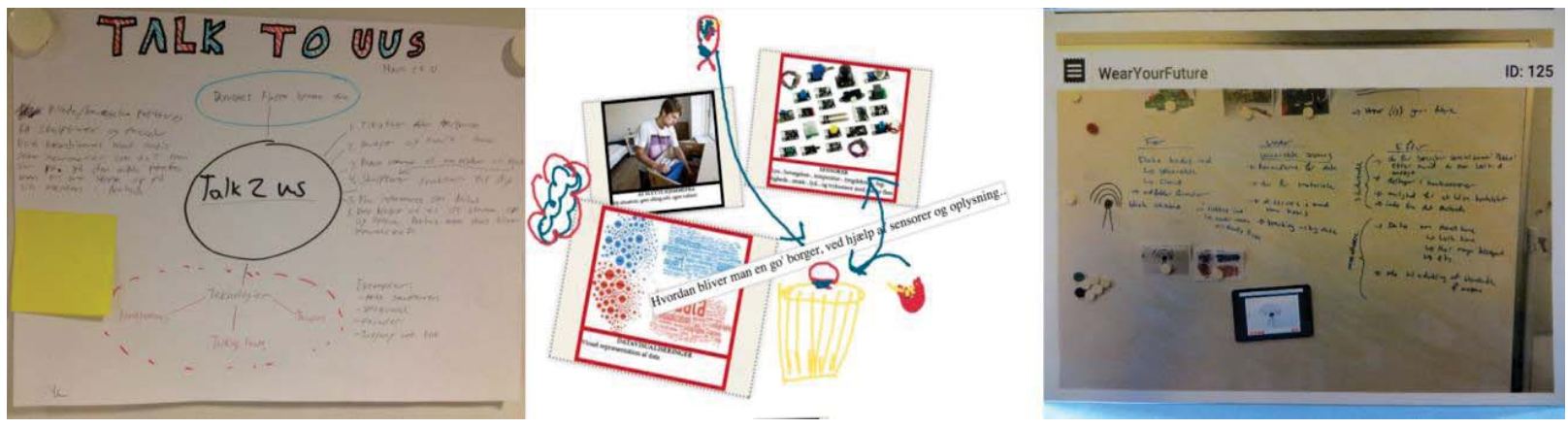

Figure 2. Pictures of design concept posters from the three setups: (left) shows a poster from ICW, and is made by hand on paper. (center) shows a poster made in iCard, consisting of a collage of digital inspiration cards, text and (right) shows a printed poster, made in RoI. The poster is a picture of the whiteboard with drawings, texts and tablets on it. 
complementary software is a web-app, which provides functions to create, store and organise the cards using the same digital repository like the iCards setup. At any time, cards can be created with any internet compatible device, quickly and simply by completing a template in the web-app. To overcome the digital barrier, every card is automatically printed via the printer in the hardware part of the RoI. This leads to a synchronized physical and digital repository of cards. Tablets and a wall display are provided but the workshop participants are free to use their own devices (smartphone, laptop, etc.) to access the digital repository. The cards are displayed next to a list, which provides organizing tools like filtering by card types, tags, highlighted cards and a full text search.

Before a workshop can start, it must be prepared by a facilitator by creating cards, but because the RoI already holds a digital and physical repository of cards, the preparation phase requires limited effort. During the preparation phase, cards can be searched in the digital and physical repository or new cards can be created through the form. By typing the ID of a physical card in the digital interface, further multimedia content (video, websites) can be explored from the digital repository. In the presentation phase, participants can use tablets and a vertical multi-touch screen to present the cards she has created or chosen. During the combination and co-creation phase, the participants of the workshop are not forced to use digital devices. However, the RoI offers some methods for supporting this phase. The tablets can be used as digital cards by opening the detail view of a card and then attaching them with the magnetic back at a whiteboard or by placing it on the table. In contrast to paper-based cards the digital one can show additional information. Also, the tablets are used to get additional external inspiration, for instance by searching the internet. To store the ideas, an outcome card - which corresponds to the concept posters in the classic Inspiration Card Workshop - can be created by choosing the corresponding card type (see Figure 2 - right). This card can also be printed and can be found in the digital list, providing new inspiration for the upcoming session. For the subsequent processing phase, the web-app sends an email with the PDF version of this card to the participants.

\section{STUDY DESIGN}

For this study, we held a session where the above presented technological variations of the idea generation event of ICW were conducted to collect data to answer the question: is it feasible to gain (some of) the benefits of digital components without detracting from the features that make physical cards beneficial in collaborative design? The three setups vary the degree of technology used during the workshop (see Table 1). With these three setups, we are able to examine the differences in the workshop, which gives an insight where technology is helpful and where it restricts the creative process.
The session was executed in a combined setup where three groups went through all three variations with 45 minutes in each setup for idea generation. The 11 participants were master students in interaction design from Aarhus University and we used their regular study groups to create three groups. Prior to this session the students were already familiar with the physical inspiration card workshop and the overall qualities of this idea generating format as well as with interaction design in general.

The groups with 4, 4 and 3 participants went through a matrix setup where each group used the physical ICW, iCard, and RoI with three different design briefs: 1) How can we inform young newcomers about Aarhus? 2) How can we make citizens in Aarhus more aware of the importance of and the possibilities of sorting of garbage? 3) How can we communicate Information Studies in an engaging way at an expo for study possibilities?

\begin{tabular}{|c|c|c|c|c|}
\hline & Presentation & $\mid \begin{array}{l}\text { Combination } \\
\text { Co-creation }\end{array}$ & Presentation & \begin{tabular}{|l} 
Subsequent \\
Processing
\end{tabular} \\
\hline \multicolumn{5}{|c|}{ ICW: Physical Inspiration Card Workshop } \\
\hline $\begin{array}{l}\text { Creation and } \\
\text { preparation of } \\
\text { physical cards }\end{array}$ & $\begin{array}{l}\text { Exploration of } \\
\text { physical cards }\end{array}$ & $\begin{array}{l}\text { Combination of } \\
\text { physical cards; } \\
\text { Creating new } \\
\text { artifacts with } \\
\text { pen and paper }\end{array}$ & $\begin{array}{l}\text { Arranging cards } \\
\text { on poster } \\
\text { sheets; }\end{array}$ & $\begin{array}{l}\text { Taking photos } \\
\text { and sharing of } \\
\text { outcome }\end{array}$ \\
\hline \multicolumn{5}{|c|}{ iCard: Digital Inspiration Card Workshop } \\
\hline $\begin{array}{l}\text { Based on web } \\
\text { repository }\end{array}$ & $\begin{array}{l}\text { Exploration of } \\
\text { digital } \\
\text { repository on } \\
\text { vertical screen }\end{array}$ & $\begin{array}{l}\text { Combination of } \\
\text { cards on } \\
\text { tabletop. }\end{array}$ & $\begin{array}{l}\text { Digital posters } \\
\text { are presented } \\
\text { on vertical } \\
\text { screen }\end{array}$ & \begin{tabular}{|l} 
Posters saved \\
as PDF files for \\
distribution
\end{tabular} \\
\hline \multicolumn{5}{|c|}{ Rol: Rack of Inspiration: Hybrid Inspiration Card Workshop } \\
\hline $\begin{array}{l}\text { Physical } \\
\text { repository is } \\
\text { automatically } \\
\text { created }\end{array}$ & $\begin{array}{l}\text { Exploration of } \\
\text { physical cards }\end{array}$ & $\begin{array}{l}\text { Combination of } \\
\text { physical Cards }\end{array}$ & $\begin{array}{l}\text { Arranging cards } \\
\text { and artifacts on } \\
\text { design area }\end{array}$ & $\begin{array}{l}\text { Storing the } \\
\text { ideas in the } \\
\text { physical } \\
\text { repository }\end{array}$ \\
\hline $\begin{array}{l}\text { Creating Cards } \\
\text { via web-app }\end{array}$ & $\begin{array}{l}\text { Exploration of } \\
\text { digital } \\
\text { repository on } \\
\text { tablets and } \\
\text { vertical screen }\end{array}$ & $\begin{array}{l}\text { Explore } \\
\text { additional } \\
\text { sources via the } \\
\text { provided } \\
\text { hardware }\end{array}$ & $\begin{array}{l}\text { Creation of } \\
\text { Outcome Cards }\end{array}$ & $\begin{array}{l}\text { Storing the } \\
\text { ideas in the } \\
\text { digital repo- } \\
\text { sitory and send } \\
\text { via email }\end{array}$ \\
\hline
\end{tabular}

Table 1. Overview of how the tools support the ICW in the different phases. Blue: physical and green: digital.

The inspiration cards for each design brief went through iterations in coordination meetings before the event in order to make the three situations as similar as possible but at the same time keeping some differences in order to limit the possibility of copying ideas from one brief to another.

We held the event in local university facilities in Aarhus where each setup was placed in a separate room. In each room, we had a facilitator to introduce the setup, the brief, the inspiration cards, and to be a time manager.

After each round, participants were asked to evaluate their ideas. Furthermore, they were asked to fill the Creativity Support Index questionnaire (CSI). At the end of the session we had a concluding group interview with each group to gain insights into the participants' reflection and share their thoughts about their experiences with the three idea generation setups.

Video recordings of the setups and transcriptions of the interviews were coded in Nvivo by the research team. In the 
first round of exploring the data, each action and statement were tagged ("criticise ICW/RoI/ICB", "use an inspiration card", "draws on whiteboard" etc.) and we used these as codes we could use on similar actions which resulted in a list of more than 150 codes. From this initial coding, we made a new list of categories combining first round codes to get an overview of possible themes which resulted in overall themes like: criticism of methods, collaboration, use of materials, with subcategories to each theme (e.g. "critical/positive towards digital/analogue elements"). After the categorization in themes, we identified a set of findings that could be connected to the five ICW method principles and the support of these, which we present below.

\section{QUANTITATIVE ANALYSIS AND INTERPRETATION}

Each idea created via the three ideation setups was rated by the participants. They were evaluated through a scheme of three parameters which they should rate in a scale from 1-5 (5 best).

A) The concept's degree of articulation: How well is the idea explained and is the representation understandable?

B) The concept's degree of completeness: How "done" and ready is the idea for implementation and execution?

C) The concept's degree of usability: Is it likely that the idea can be put in a use context and has the qualities to be used and have purpose?

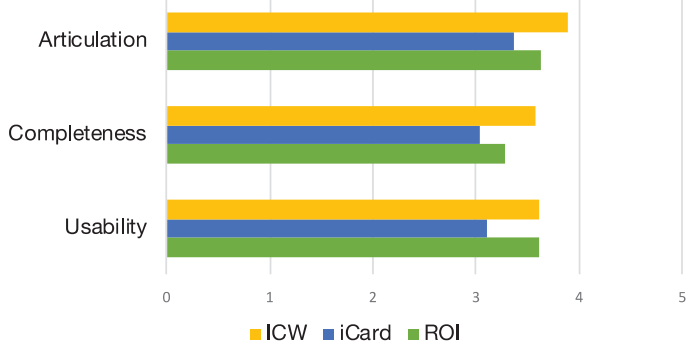

Figure 3. Setup ratings

The ratings of the three setups with respect to the three parameters shows that the physical setup performs slightly better (see Figure 3). The ideas created via the iCard setup always scored lowest. So, there seems to be a trend towards the physical setups. However, from these marginal differences an interpretation of which setup leads to better ideas cannot be concluded.

In addition to the rating a creativity support index is calculated from a questionnaire called CSI designed for evaluating the ability of a creativity support tool to assist a user engaged in creative work. "[6] the CSI, measures how well a system or tool supports creative, open-ended activities, and it is grounded in literature about creativity support tools, creativity, play, and flow." [6]. It consists out of 6 parameters: Exploration: considering different options and tracking of ideas, Expressiveness: ability of being selfexpressive, Collaboration: sharing of ideas and working together, Results worth Effort: satisfaction of outcome, Immersion: attention engrossed by the system and
Enjoyment: enjoyment of use. Each parameter is acquired with two questions, giving a rating on a scale of 1-10. Figure 4 shows the rating of the three ideation setups with the six parameters.

In Figure 4 it can be observed that the same trend occurs as in the idea rating. The physical setup was rated similar and also higher than the digital iCard setup.

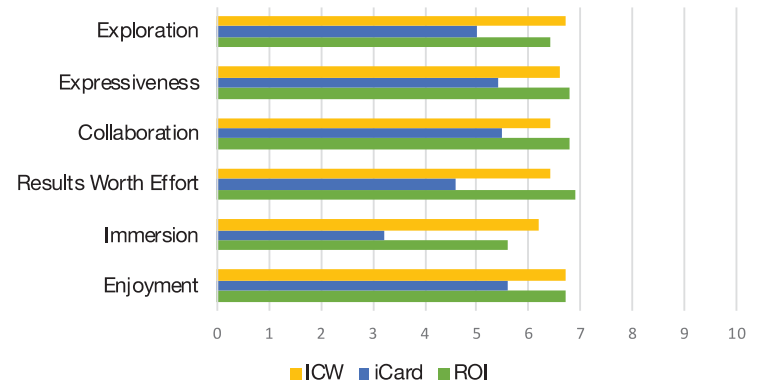

Figure 4. CSI score of setups by parameter, ordered by its count.

Furthermore, each parameter was weighted by the participants between 1-5. This score, called count, indicates the importance of the parameters for the participants and is used for weighting the score achieved in the completed task. From the weighting of CSI parameters can be derived that the parameters Exploration (avg. 3.9) and Expressiveness (avg. 3.4) were the most important for the participants during the workshop. Collaboration (avg. 2.4) and Results Worth Effort (2.3) scored the middle. Immersion (avg. 1.6) and Enjoyment (avg. 1.4) scored lowest.

ICW and RoI perform a very similar score, indicating an equal level of support of the creative process. The digital tools within the RoI seem neither to be restricting nor enhancing the support significantly. The lower score in the iCard indicates that the technology used during the workshop reduces the level of support in the ideation process.

The quantitative data shows that creativity is supported differently by the tools, but the quality of the ideas was rated similarly. There is a slight correlation between the CSI and the quality of the ideas, the iCard with the lowest CSI score also generated ideas with slightly lower quality. To examine the identified trend that physical setup was rated better, we analyse the qualitative data gathered during the three workshops.

\section{QUALITATIVE ANALYSIS}

By analysing the qualitative data, the observed trends from the quantitative data could be explored further. The group interviews revolved around seven topics: collaboration, individual/social idea generation, combination of sources of inspiration, strengths and weaknesses, preferred method for future use, the quality of ideas and interface. During the interviews, each group was asked to reflect on each topic and compare their experiences using the three setups. 
Video recordings and transcriptions of the interviews were coded in Nvivo by the research team. In the first round of exploring the data, each action and statement was tagged ("critizise ICW/RoI/ICB", "use an inspiration card", "draws on whiteboard" etc.) and we used these as codes we could use on similar actions which resulted in a list of more than 150 codes. From this initial coding, we made a new consolidated list of categories combining first round codes to get an overview of possible themes which resulted in overall themes like: criticism of methods, collaboration, use of materials, with subcategories to each theme (e.g. "critical/positive towards digital/analogue elements"). After the categorization in themes, we identified a set of findings that could be connected to the five ICW method principles and the support of these, which we present below.

\section{No prerequisite skills and simple rules}

\section{Finding 1.1: Simple hardware setups invite use, whereas} complex setups impede it.

The RoI hardware setup is described in the interviews as being complex, which might explain why the groups use very different approaches using primarily the physical cards for creating an overview. One participant suggests having only a whiteboard, an iPad and a printer to accommodate for this (Interview, group 2). Another participant suggested scaling the size of the cards in the digital list down on the large screen, so that more cards could be seen at once. In the group interviews, the RoI setup was criticized by some participants with respect to elements that were not necessary in the idea generation process: the touch screen on the wall was considered too big, while the "rack" was seen as an unnecessary element in this setup.

\section{Finding 1.2: Physical materials seem to support more fluent interaction.}

One participant suggests that the physical elements may offer better flow because they are faster to use: "So I think it's again about the context. If you just need to start something quickly, with some kind of flow, I think the more physical (elements) would be better" (Interview, group 1). This experience may have to do with the accessibility of the tools, as most people are used to working with pen and paper on a regular basis, and a deck of inspiration cards are clearly easier to move around with compared to how they experience the web-app of the RoI and the iCards table.

\section{Finding 1.3: Ease of making new inspiration cards is valuable.}

In RoI and ICW there are several examples of participants making their own inspiration cards, an option not available in iCard, which Group 1 asked for. In ICW the participants make quick sketches or write a headline on blank cards. In RoI they use the website with the available tablets to take a photo of elements in the room, add text and then print out the new inspiration card.
In summary, using familiar basic tools and material is an important enabler of participation, and, in particular, in the case of creativity sessions, which can develop their own dynamics due to the flow of activity. It is crucial to find the right mixture of physical and digitals tools, which on the one hand guide the process, and on the other hand offer freedom and space for creativity.

\section{Mutual Learning}

\section{Finding 2.1: Simultaneous overview of all cards facilitates mutual learning.}

There was a clear consensus in the groups that RoI did not offer much overview of inspiration cards. One participant explained this by comparing ICW and iCard: "It's because all the cards are placed on each their side, so that you can't actually get the big overview, as you can when they are laying on the table or when they were down at the screen [...]" (Interview, group 2). The interviews reveal that iCard was experienced as having both pros and cons in relation to letting the groups have an overview of the inspiration cards. In general, we observed that the vertical screen was used for the presentation phase, in which the participants discussed the different available cards on the screen, and thus getting an overview of both the domain cards and the technology cards. The horizontal screen was on one hand described as being confusing, since the inspiration cards were organized in small, overlapping stacks laid out along the edges of the horizontal screen. On the other hand, since the combination phase of inspiration cards was confined to the horizontal screen, this "forced collaboration" was articulated as giving an overview to the group of what each participant was doing (Interview, group 2).

\section{Finding 2.2: Supporting card organization is an important part of mutual learning.}

The groups often started by clustering the domains and technologies in order to get an overview of the design space - in the classical sense of all possible potential design solution [8,30]. In general, the groups would frame the problem by orienting themselves in the available cards, clarify their understanding of the design brief and discuss personal experiences related to the design brief. After this, the group started discussing ideas based on the cards. On the whole, providing an overview of both kinds of cards is an important basis for establishing a shared design space as a prerequisite for mutual learning [3]. An interactive exploration of a digital repository can have many benefits. However, participants seem to prefer the physical exploration of cards instead. That may be due to the threshold that digital setups present. Future setups for the exploration of digital repositories should try to lower the threshold to entry like physical cards do. On the other hand, easy access to a digital repository providing multimedia material like video is valuable for mutual learning. Digital features like filtering, searching, and tagging would be very much appreciated in future setups. 


\section{Collaborative Ideation}

Finding 3.1: Workflow is challenged when the interface does not allow for simultaneous interaction.

The most prominent difference between setups that integrate digital tools and setups that are purely physical, is that disruptions of the continuity can be experienced when the interface does not allow for simultaneous interaction: "Some ideas can be lost because you are thinking something, but are not able to write it down, not able to do something with it, [...] because others are working, so you have to wait and maybe you've forgotten it, or you have moved to talk about something else" (Interview, group 2). Holding back one's own idea is explained by one participant as a result of respect of each individual's progress or continuity.

\section{Finding 3.2: There are both pros and cons for supporting individual idea generation.}

One group articulated positive comments about the lack of individual idea generation possibilities and individual space in the iCard setup, which they considered to be an asset with iCard as explained by one of the participants "This table (iCard) really did not support anything for the individual. You did not have any post-its you could sit with and write down ideas on. It was either collaboration or nothing." (Interview, group 3). Concerning forced collaboration, the group also expressed in response to the question about their favourite idea, that it was the last idea created in the iCard that was the best, because the idea had no ownership and everyone was a part of the development. The forced collaboration was not considered as a positive quality among the two other groups, who appreciated the opportunity to write your own thoughts down while not disturbing other participants. One participant says about the iCard setup that you feel a bit stupid when everyone is watching everything you do because of the limit with only one person that can interact with the table at a time.

\section{Finding 3.3: The ability to share tasks between group members to enhance efficiency is a key component of good collaboration.}

When the groups were asked about collaboration they addressed the possibility of doing different tasks simultaneously. A participant's positive evaluation of the two methods involving physical materials, ICW and RoI, was explained by: "There were different tasks you could do simultaneously to create results faster and better." (Interview, Group 1). Figure 5 show examples of dealing with different elements at the same time in the process. The picture to the left, shows group 2 in the ICW setup while a participant is gluing inspiration cards on a poster. Two participants have moved on to the next idea inspired by the first one. In this situation a participant is handing over a blank inspiration card to another while the last participant is looking at her phone. The picture to the right shows group 1 finishing an idea while getting ready to make a new one: A facilitator helps a participant with the web application because he is experiencing problems about making a poster card. Another participant is cleaning the whiteboard for text and drawings while the third participant returns the inspiration cards to the rack. We examined benefits and drawbacks from observed collaboration. On the one hand, if

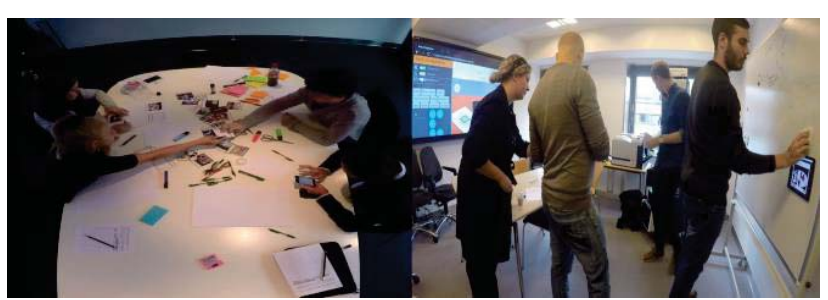

Figure 5. In the RoI and ICW setup there were several examples where participants took care of different tasks.

collaboration is enforced by the interface, emerging ideas cannot be elaborated in parallel. On the other hand, it can be used as a focus, where all participants work concentrated on the same idea. Clearly, the iCard setup is a single input tabletop, which caused participants to await their turn and thus reduced productivity. The majority of the participants seems to favour support for working both individually and collaboratively, and the current digital implementation hinders the transition between working individually and working collaboratively. This suggests that a digital setup should provide simultaneous interaction to grant seamless transition between individual and collaborative work. But transferring the freedom of physical coordination to a digital setup is a challenge.

\section{Combinatorial Creativity}

Finding 4.1: Physical cards allow for multiple ways of arranging the cards to get an overview.

In general, the groups started the session by orienting themselves in the inspiration cards as a starting point for combining cards. In iCard, the groups stood in front of the vertical screen and looked at the grid of cards to get an overview. In ICW the groups grabbed the cards already lying randomly on the table and sorted them in domain and technology cards. When creating an overview of the design space in ICW, one group grabbed some of the cards and turned them upside down, and thereby constrained the design space by literally filtering out some of the possibilities - an option not available in the digital version.
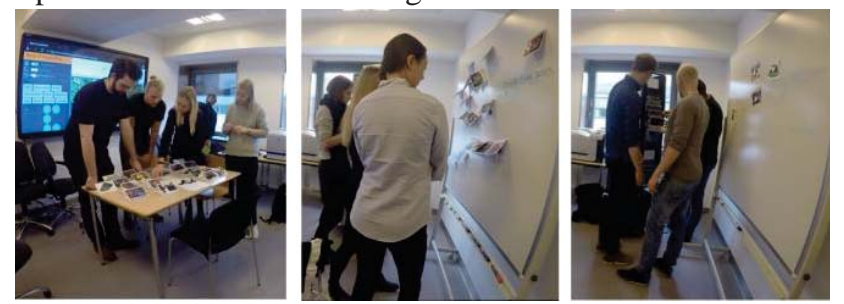

Figure 6. Card exploration with the Rack of Inspiration.

Even though the RoI offers a rack with holders containing the cards in no specific order, and a large screen displaying a list of the cards, the groups used different methods, primarily involving the physical cards, to get an overview (see Figure 6). One group took all the cards from the rack 
and place them on the table, while another group placed all the cards on a whiteboard. The third group kept the cards in their starting point in the rack, and only hung selected cards on the whiteboard to discuss ideas based on those cards.

\section{Finding 42: Physical materials offered more flexibility with respect to how to arrange cards and sketches.}

Cards, text and sketches were combined very differently in the three setups. In ICW two of the groups placed the cards they were talking about close together on the table among the other cards while the third group picked the cards up and place them on the whiteboard if they found them interesting for the specific idea. In RoI, the three groups combined cards in three ways: One group placed the cards in focus close together on the table where they had the rest of the cards, causing a bit of space problems. Another group did the same but instead placed the cards in focus on the whiteboard providing more space to work with, add notes, and sketches around the cards in focus, while the third group picked cards from the rack and placed the cards in focus on the whiteboard. With iCard the groups all had the same approach of dragging cards they found interesting into the poster-area in the middle on the table and made these cards larger using the resize function.

The physical elements in particular support the establishment of a shared understanding as the foundation of selection and combination of cards. Flexibility of arrangements is a key feature for combinatorial creativity where physical cards offer a good affordance for organising and combining cards.

\section{Externalization of ideas}

Finding 5.1: Physical tools and materials were highly flexible when participants wanted to externalise thoughts and ideas

The three groups' different uses of externalisations to visualize new ideas became very visible in the setups with physical elements. One group used sticky-notes to facilitate individual idea generation in the beginning of both RoI and ICW, and then used the sticky-notes as support when they presented their suggestions to each other. Another group used the whiteboard constantly in both RoI and ICW where they supported the shared idea generation with sketches and mind maps of the design situation, elements of the ideas and more. In the iCard setup there was no shift in materials and they only shifted between the different tools implemented in the iCard setup to externalize their ideas.

\section{Finding 5.2: Digital elements support the transition of an externalization from being transformative to informative.}

The ease of changing an idea's status from being in a transformative mode to being saved for possible recall later and making it informative with the digital elements in RoI and ICard were highly appreciated by the participants. In RoI participants only had to take a picture with the tablet of the idea generation space where they had placed cards, sketches and/or notes to create an idea poster card with the possibility of adding descriptive notes. A participant says: "One of the things I really think worked well in Rack of Inspiration was the element of condensing the idea to a card. Okay, now we are finished with that idea, one writes the idea's name and the others can clean the whiteboard and make it ready for a new idea" (Interview, group 1). In iCard you only had to press a button to save the created idea poster as a PDF and then it was stored for later use. The participants encountered a bit more work when creating posters for the physical ICW. For instance, they had to copy used cards on blank cards or write down the title of the used cards if they wanted to reuse them. Otherwise they glued the cards on the poster making the cards not available to use in other ideas.

\section{Finding 5.3: Altering cards happened rarely and only in the digital setup}

The cards were used in their original, unaltered form in the ICW and RoI setups, ie. the participants did not draw on them or annotate them. Only in the iCard setup we observed that participants drew on the inspiration cards and placed notes (text boxes) on top of the cards. As an example, Group 2 wanted to have a card that represented a person. They dragged a technology card with Tony Oursler's installation "Ello" to the poster space and drew a hat and a moustache on the card, in their own words during the workshop, to make it look more like a person. Another example from group 1 was where they used a card to represent the theme of the idea. They thought the original title and description on the card were not suitable for their idea and therefore, they drew on top of the text field on the card and placed a text box they made themselves on the card.

In summary, digital and physical tools as well as materials in the current setups each have their strengths and weaknesses with respect to supporting externalisations. Especially the physical elements have proved to be flexible and powerful.

\section{LIMITATIONS}

Our study has a number of limitations, which must be taken into account when assessing the findings and potential implications. The main focus of this paper is the digital enhancement of an existing creativity method, which strongly rely on physical card-based artifacts. Therefore, a digital enhancement cannot unroll all its potential benefits (e.g. remote collaboration). Furthermore, our studied method is specialised in the integration of sources of inspiration into the design process. Hence the study result cannot be generalized for the diverse and large number of creativity methods. Moreover, it is possible that the slightly different spatial layouts of the three different setups, as well as possible differences in personality traits among participants have influenced the findings. We did, however, strive to minimize these two factors by installing the systems in similar rooms and recruiting study participants with similar educational backgrounds and skillsets regarding design expertise. 


\section{CONCLUSION}

The quantitative and especially the qualitative analysis provide interesting insights into the usage of physical and digital tools during a creative design session.

The quantitative data showed a trend that participants prefer physical tools, which was confirmed by an in depth qualitative analysis (see Finding 1.2, 2.2, 3.3, 4.1, 4.2, 5.1). In general, the seemingly simple physical tools like cards, pencils, tables, whiteboards and posters provide a good overview, smooth dynamics of idea generation, and support both individual and collaborative activities. Especially the use of physical cards reveals many benefits during the workshop phases: intuitive method of exploration, flexible organizational possibilities, versatile manner of selection and combination of cards, a good support of the creativity flow and affordance for interaction.

iCard and RoI provided heterogeneous hardware settings (tabletop, large vertical screen, tablets, printer). One major insight of our study is that participants perceived these hardware settings as being too complex (see Finding 1.1). Taking a look at the different devices the iCard table obstructed collaboration in several instances. Its main drawbacks are the lack of support for the flexibility of heterogeneous workspace arrangements and limited multiuser support. The large vertical screen in the iCard and in the RoI setup allowed for exploration of the digital repository and offered powerful digital functionalities (see Finding 1.1, 2.1, 3.1, 5.3). But once again participants seem to prefer the physical exploration of cards instead.

The only hardware setting which seems to support the principle no prerequisite skills and simple rules is the tablet/printer combination. Being the integral part of the hybrid RoI setups the participants feel secure enough to explore digital functionalities. The participants used these digital tools and integrated them seamlessly into their own work practice (see Finding 1.3, 5.2). Overall, the combination of tablets and a printer showed some clear benefits for the creative process.

Our overall conclusion is that physical tools are extremely powerful and that they cannot be substituted completely by digital tools. However, if both physical and digital tools were offered, participants made use of the freedom to switch between them. Therefore, digital tools can enhance the creativity of the overall workshop but they have to be integrated carefully into the existing workflow. Our findings have shown that the tablet/printer combination is a good combination for enhancing the overall workshop process. In Table 3 we present a lightweight integration of tablets/printer devices into the ICW workflow. In this hybrid cross-device setting each group member will be equipped with a least one tablet and a stylus. The tablets are the "windows to the digital world" (e.g. web, digital repositories of idea cards) and allow the group members to access digital content and to integrate this content in the physical setting.

The interactive behaviour of tablets as digital tools is closest to paper cards as physical tools. Together with the printer they support an easy transmission form the digital to the physical world. Tablets offer easy access to a digital repository of ideas (e.g. the web or a specific digital repository with idea cards) and can be used to generate new (technical or domain) cards. For easy handling these digital cards can be printed and smoothly integrated in the whole creativity process. Therefore, the printer plays a key role in this integration process printing all sort of cards (technical, domain, idea) on the fly and make them available for combinatorial creativity. Another benefit of tablets is the possibility of presenting multimedia content (e.g. videos or animations) which is not possible with physical cards.

Physical Cards

Tablets/ Printer

Creation and preparation of physical cards offer a required

starting point for the overall workshops. Using familiar basic

tools and materials is an important enabler of participation.

Tablets offer an access to the digital repository. Cards can therefore be created easily. Furthermore, an additional collection of cards can be prepared for later use.

Physical cards can be explored and presented to each other.

Additional multimedia information from the repository and the web can be accessed and presented. This can enrich the mutual learning process. Furthermore, the digital repository can be explored by each participant and the set of physical cards can be extended through the printing of cards from the digital repository. Through these possibilities a collaborative ideation process can be supported.

Physical cards can be combined and new artifacts can be created via pen and paper.

Tablets can be used to create entirely new cards. On the one hand, cards can be created via online sources. On the other hand, sources can be captured by using the devices camera. These functions allow new the devices camera. These functions allow new
possibilities for a combinatorial creativity.

Arranging cards and artifacts on a whiteboard; Arranging cards and artifacts within a design area.

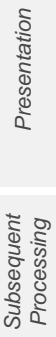

Tablets can be used as physical artifacts as well. They can serve as digital cards which can be easily integrated into the arrangements of physical cards. Therefore, the physical workflow based on physical cards is enhanced and the externalization of ideas can be supported by digital information.

Storing the ideas in the physical repository

Ideas can be stored in the digital repository. Each participant can access this repository for later use. Created ideas can be used as a starting point and as new sources of inspiration for further workshops.

Table 3. Lightweight Hybrid Workflow based on Cards and Tablets \& Printer

However, whether our recommended lightweight hybrid workflow offers the right balance between the power of digital tools and the complexity of their use is an open question for further research.

\section{ACKNOWLEDGEMENT}

This research was funded by Innovation Fund Denmark (grant 1311-00001B, CIBIS).

\section{REFERENCES}

1. Valter Alves and Licinio Roque. 2011. A deck for sound design in games: enhancements based on a 
design exercise. In Proceedings of the 8th International Conference on Advances in Computer Entertainment Technology (ACE '11), Teresa Romão, Nuno Correia, Masahiko Inami, Hirokasu Kato, Rui Prada, Tsutomu Terada, Eduardo Dias, and Teresa Chambel (Eds.). ACM, New York, NY, USA, Article 34, 8 pages. http://dx.doi.org/10.1145/2071423.2071465

2. Teresa M. Amabile. 1983. The social psychology of creativity. New York: Springer-Verlag.

3. Michael Mose Biskjaer, Peter Dalsgaard, and Kim Halskov. 2014. A constraint-based understanding of design spaces. In Proceedings of the 2014 conference on Designing interactive systems (DIS '14). ACM, New York, NY, USA, 453-462. https://doi.org/10.1145/2598510.2598533

4. Margaret A. Boden. 2004. The Creative Mind: Myths and Mechanisms. London: Routledge. /Psychology Press.

5. Jacob Buur and Astrid Soendergaard. 2000. Video card game: an augmented environment for user centred design discussions. In Proceedings of DARE 2000 on Designing augmented reality environments (DARE '00). ACM, New York, NY, USA, 63-69. http://dx.doi.org/10.1145/354666.354673

6. $\quad$ Erin Cherry and Celine Latulipe. 2014. Quantifying the Creativity Support of Digital Tools through the Creativity Support Index. ACM Trans. Comput.-Hum. Interact. 21, 4, Article 21 (June 2014), 25 pages. http://dx.doi.org/10.1145/2617588

7. Alan Dix and Layda Gongora. 2011. Externalisation and design. In Procedings of the Second Conference on Creativity and Innovation in Design (DESIRE '11). ACM, New York, NY, USA, 31-42.

http://dx.doi.org/10.1145/2079216.2079220

8. Graham Dove, Nicolai Brodersen Hansen, and Kim Halskov. 2016. An Argument For Design Space Reflection. In Proceedings of the 9th Nordic Conference on Human-Computer Interaction (NordiCHI '16). ACM, New York, NY, USA, Article 17, 10 pages. https://doi.org/10.1145/2971485.2971528

9. Itiel E. Dror and Stevan Harnad. 2008. Offloading cognition onto cognitive technology. In Cognition distributed: How cognitive technology extends our minds, Itiel E. Dror and Stevan Harnad (eds.).
John Benjamins, Amsterdam, the Netherlands, 123

10. Brian Eno and Peter Schmidt. 1978. Oblique strategies. Opal, London.

11. Gerhard Fischer, Elisa Giaccardi, Hal Eden, Masanori Sugimoto, and Yunwen Ye. 2005. Beyond binary choices: Integrating individual and social creativity. International Journal of HumanComputer Studies, 63, 4 (October 2005), 482-512. https://doi.org/10.1016/j.ijhcs.2005.04.014

12. Henrik Gedenryd. 1998. How designers work: Making sense of authentic cognitive activities. Ph.D Dissertation. University of Lund, Sweden. http://portal.research.lu.se/ws/files/4819156/14842 53.pdf

13. Florian Geyer, Ulrike Pfeil, Anita Höchtl, Jochen Budzinski, \& Harald Reiterer. 2011. Designing reality-based interfaces for creative group work. In Proceedings of the 8th ACM conference on Creativity and cognition (C\&C '11). ACM, New York, NY, USA, 165-174. http://dx.doi.org/10.1145/2069618.2069647

14. Joan Greenbaum and Morten Kyng. 1991. Design at Work: Cooperative Design of Computer Systems. L. Erlbaum Associates Inc. Hillsdale, NJ, USA.

15. Joshua Hailpern, Erik Hinterbichler, Caryn Leppert, Damon Cook, and Brian P. Bailey. 2007. TEAM STORM: demonstrating an interaction model for working with multiple ideas during creative group work. In Proceedings of the 6th ACM SIGCHI conference on Creativity \& cognition (C\&C '07). ACM, New York, NY, USA, 193-202. http://dx.doi.org/10.1145/1254960.1254987

16. Kim Halskov. 2011. CAVI - An interaction design research lab. interactions, 18(4). 92-95.

17. Kim Halskov and Nicolai Brodersen Hansen. 2015. The diversity of participatory design research practice at PDC 2002-2012. International Journal of Human-Computer Studies 74 (February 2015). 81-92. https://doi.org/10.1016/j.ijhcs.2014.09.003

18. Kim Halskov and Peter Dalsgård. 2006. Inspiration card workshops. In Proceedings of the 6th conference on Designing Interactive systems (DIS '06). ACM, New York, NY, USA, 2-11. http://dx.doi.org/10.1145/1142405.114240 
19. Kim Halskov and Peter Dalsgaard. 2007. The Emergence of Ideas: the interplay between sourcesof inspiration and emerging design concepts. CoDesign - International Journal of CoCreation in Design and the Arts, 3, 4 (June 2008). 185-211. https://doi.org/10.1080/15710880701607404

20. Björn Hartmann, Meredith Ringel Morris, Hrvoje Benko, and Andrew D. Wilson. 2010. Pictionaire: supporting collaborative design work by integrating physical and digital artifacts. In Proceedings of the 2010 ACM conference on Computer supported cooperative work (CSCW '10). ACM, New York, NY, USA, 421-424. https://doi.org/10.1145/1718918.1718989

21. James Hollan, Edwin Hutchins, and David Kirsh. 2000. Distributed cognition: toward a new foundation for human-computer interaction research. ACM Trans. Comput.-Hum. Interact. 7, 2 (June 2000), 174-196. https://doi.org/10.1145/353485.353487

22. William Hudson. 2005. Playing your cards right: getting the most from card sorting for navigation design. interactions 12, 5 (September 2005), 5658. http://dx.doi.org/10.1145/1082369.1082410

23. IDEO. 2003. Method cards: 51 ways to inspire design. Palo Alto.

24. James C. Kaufman \& Roger J. Sternberg. 2010. The Cambridge handbook of creativity. Cambridge University Press. USA.

25. Arthur Koestler. 1978. The act of creation. (1964). Pan Books. London, England.

26. Vijay Kumar. 2012. 101 design methods: A structured approach for driving innovation in your organization. John Wiley \& Sons. Hoboken, NJ, USA.

27. Andrés Lucero and Juha Arrasvuori. 2010. PLEX Cards: a source of inspiration when designing for playfulness. In Proceedings of the 3rd International Conference on Fun and Games (Fun and Games '10). ACM, New York, NY, USA. 2837. http://dx.doi.org/10.1145/1823818.1823821

28. Andrés Lucero and Juha Arrasvuori. 2012. The PLEX Cards and its techniques as sources of inspiration when designing for playfulness. International Journal of Arts and Technology 6, 1. 22-43. https://doi.org/10.1504/IJART.2013.050688
29. Andrés Lucero, Peter Dalsgaard, Kim Halskov, and Jacob Buur. 2016. Designing with Cards. In Collaboration in Creative Design, Panos Markopoulus, Jean-Bernard Martens, Julian Marlins, Karin Coninx, and Aggelos Liapis (eds.). Springer International Publishing. Switzerland. 75-95.

30. Allan MacLean, Richard M. Young, Victoria M. E. Bellotti, and Thomas P. Moran. 1991. Questions, options, and criteria: Elements of design space analysis. Human-computer interaction 6, 3-4 (June 2011), 201-250. 10.1080/07370024.1991.9667168

31. Michael Michalko. 2010. Thinkertoys: A handbook of creative-thinking techniques. Ten Speed Press. Berkeley, California, USA.

32. Lora Oehlberg, Kyu Simm, Jasmine Jones, Alice Agogino, and Björn Hartmann. 2012. Showing is sharing: building shared understanding in humancentered design teams with Dazzle. In Proceedings of the Designing Interactive Systems Conference (DIS '12). ACM, New York, NY, USA, 669-678. https://doi.org/10.1145/2317956.2318057

33. Florian Perteneder, Christian Grossauer, Thomas Seifried, Jagoda Walney, John Walney, John Brosz, Anthony Tang, Sheelaugh Carpendale, and Michael Haller. 2012. Idea playground: When brainstorming is not enough. In Designing Collaborative Interactive Spaces for e-Creativity, e-Science and e-Learning Workshop, AVI.

34. Douglas Schuler and Aki Namioka, eds. 1993. Participatory design: Principles and practices. CRC Press. Hillsdale, NJ, USA.

35. Jesper Simonsen and Toni Robertson. 2012. Routledge Handbook of Participatory Design. Routledge, London.

36. Gerald F. Smith. 1998. Idea-generation techniques: a formulary of active ingredients. In The Journal of Creative Behavior 32, 2 (first published December 2011), 107-134. https://doi.org/10.1002/j.21626057.1998.tb00810.x

37. Michael W. Tschudy, Elizabeth A. DykstraErickson, and Matthew S. Holloway. 1996. PictureCARD: A storytelling tool for task analysis. In Proceedings of the $4^{\text {th }}$ Biennial Participatory Design Conference (PDC'96). 183191. 
38. Edward Tse, Saul Greenberg, Chia Shen, Clifton Forlines, and Ryo Kodama. 2008. Exploring true multi-user multimodal interaction over a digital table. In Proceedings of the 7th ACM conference on Designing interactive systems (DIS '08). ACM, New York, NY, USA. 109-118.

http://dx.doi.org/10.1145/1394445.1394457

39. Christiane Wölfel, and Timothy Merritt. 2013. Method card design dimensions: a survey of cardbased design tools. In IFIP Conference on Human-Computer Interaction, Springer Berlin Heidelberg. 479-486. https://doi.org/10.1007/9783-642-40483-2_34 